\title{
Allometric Associations between Body Size, Shape, and 100-m Butterfly Speed Performance
}

\section{Running title: Allometric model and butterfly stroke performance}

Senda Sammoud ${ }^{1}$, Alan Michael Nevill ${ }^{2}$, Yassine Negra ${ }^{1}$, Raja Bouguezzi ${ }^{1}$,Helmi Chaabene ${ }^{4}$, and Younés Hachana ${ }^{1-3}$

${ }^{1}$ Research Unit "Sport Performance Health and Society" Higher Institute of Sport and Physical Education of Ksar Said, Tunis, Tunisia2

${ }^{2}$ Faculty of Education, Health, and Wellbeing, University of Wolverhampton, Walsall, UNITED KINGDOM;

${ }^{3}$ Higher Institute of Sports and Physical Education, Manouba University, Tunis, Tunisia

${ }^{4}$ Tunisian Research Laboratory "Sports Performance Optimization", National Center of Medicine and Science in Sports (CNMSS), Tunis, Tunisia

\section{Acknowledgments:}

The authors thank the "Ministry of Higher Education and Scientific Research, Tunis, Tunisia" for financial support.

\section{Corresponding author:}

Dr. Yassine Negra

Email: negrayassine@yahoo.fr

Research Unit "Sport Performance Health and Society» Higher Institute of Sport and Physical Education of Ksar Said, Tunis, Tunisia

Phone: +21654100140 


\begin{abstract}
:
BACKGROUND: This study aimed to estimate the optimal body size, limb-segment length, and girth or breadth ratios associated with $100-\mathrm{m}$ butterfly speed performance in swimmers.METHODS: One-hundred-sixty-seven swimmers as subjects (male: $n=103$; female: $n=64)$. Anthropometric measurements comprised height, body-mass, skinfolds, armspan, upper-limb-length, upper-arm, forearm, hand-lengths, lower-limb-length, thigh-length, leg-length, foot-length, arm-relaxed-girth, forearm-girth, wrist-girth, thigh-girth, calf-girth, ankle-girth, biacromial and biiliocristal-breadths. To estimate the optimal body size and body composition components associated with 100-m butterfly speed performance, we adopted a multiplicative allometric log-linear regression model, which was refined using backward elimination. RESULTS: Fat-mass was the singularly most important whole-body characteristic. Height and body-mass did not contribute to the model. The allometric model identified that having greater limb segment length-ratio [arm-ratio $=($ arm-span $) /$ (forearm) $]$ and limb girth-ratio [girth-ratio $=$ (calf-girth)/ (ankle-girth)] were key to butterfly speed performance. A greater arm-span to forearm-length ratio and a greater calf to ankle-girth-ratio suggest that a combination of larger arm-span and shorter forearm-length and the combination of larger calves and smaller ankles-girth may benefit butterfly swim speed performance. In addition having greater biacromial and biiliocristal breadths is also a major advantage in butterfly swimming speed performance. Finally, the estimation of these ratios was made possible by adopting a multiplicative allometric model that was able to confirm, theoretically, that swim speeds are nearly independent of total body size. CONCLUSION: The 100-m butterfly speed performance was strongly negatively associated with fat mass and positively associated with the segment length ratio [(arm-span)/ (forearm-length) and girth ratio (calfgirth)/(ankle-girth), having controlled for the developmental changes in age.
\end{abstract}

Key Words: Allometric model, butterfly stroke, anthropometric measurements 


\section{Introduction:}

Performance success in swimming is dependent upon a variety of factors including the physical and the physiological attributes of the swimmers, their technical, tactical, and psychological skills' level. ${ }^{1}$ Some of these factors are not easily measured objectively, but others can be accurately tested using standardized methods that may provide useful information for coaches. Marked evidences suggested that swimmers' anthropometric characteristics are one of the most critical factors that allow to achieve high performance levels in swimmer athletes. ${ }^{2-5}$ In this context, Fritzdorf et al. ${ }^{2}$ reported that taller and bigger swimmers can produce more force per-stroke as long as their stroke length is longer, however, smaller swimmers cannot achieve such long stroke lengths; as a result, they utilize a higher stroke rate. In a sample of 12-years old male swimmers, Avlonitou, ${ }^{6}$ revealed that there were differences between swimming events for height, arm-length, and leg-length and that these variables were significantly associated with swimming performance. According to the same researcher, taller swimmers with longer arms achieved faster 50-m front crawl times than swimmers of shorter height and arm-lengths. Similarly, Perezet al. ${ }^{7}$ found significant correlations between the average swimming speed and upper and forearm-length, handlength, arm-span, and biacromial-breadth. Geladas et al. ${ }^{3}$ outlined the difference between genders and revealed that upper extremity length was associated to $100-\mathrm{m}$ freestyle performance in males while upper extremity length, height, and hand-length were significantly related to performance in females (12 to 14 years).

The arm-span, notably, seems to be one of the major performance determinants as it is correlated with stroke mechanics, namely the stroke length (the distance that swimmer moves forward per stroke) and stroke index (it is an estimator for swimming efficiency) in 400-m front crawl among prepubertal (11years) and pubertal (14years) male swimmers. ${ }^{4}$ Latt et al. ${ }^{8}$ found that both arm-span and stroke index were two key predictors in 100-m freestyle event in male adolescent swimmers (15years). Similarly, Morais et al. ${ }^{9}$ indicated that arm-span was the principal anthropometric factor in predicting swimming performance within adolescent swimmers of both genders (12years). In agreement with the previous statement, Jürimäe et al.

${ }^{4}$ showed that, alongside VO2peak, arm-span was the best anthropometric predictor of $400-\mathrm{m}$ freestyle performance in prepubertal (14years) and postpubertal swimmers (11years).Despite the existing studies, the influence of anthropometric measurements (body size, body composition, and limb segment lengths) on swimming performance within pediatric and adolescent athletes is still considered a matter of debate. 
For instance, to compare physical qualities of two or more mutually exclusive groups that might also differ in body size, there is a need to remove or adjust the confounding effect of body size before valid inference about the differences in physical activity/ performance can be made. ${ }^{10}$ The matter of "scaling" and/or adjusting physiological variables (e.g., maximal or peak oxygen uptake) for differences in body size has been the subject of numerous scientific publications. ${ }^{5,11}$ Recently, Nevill et al. ${ }^{5}$ applied an allometric modeling approach to estimate the optimal body size and limb-length segment associated with 100-m front crawl speed performance in youth swimmers (11 to 16 years). Results from this study showed that fat free mass was the most relevant whole-body characteristics and that height and body mass did not contribute to the model highlighting the fact that the advantage of longer levers was mainly limb-specific. Also, they reported that greater limb segment length ratio (i.e., arm ratio = $[$ forearm $] /[$ upper-arm]; foot-to-leg ratio $=[$ foot $] /[$ lower-leg $]$ ) was associated with personal best swim speed. However, the same authors did not take into account the mass volume and/or the girth of the associated segment suggesting that further studies still need to be explored in this way. Additionally, given that the question regarding the influence of body size and composition, as well as limb segment lengths and circumference on butterfly swimmer's performance in children and adolescents remains unanswered, the purpose of this study was to use allometric model to estimate the optimal body size and limb segment length, girth or breadth ratios associated with 100-m butterfly speed performance in elite-level children and adolescents swimmers.

\section{Materials and Methods}

\section{Experimental approach to the problem:}

This study adopted allometric models to estimate the optimal body size and limb segment length, girth or breadth ratios associated with 100 -m butterfly speed performance in national level youth swimmers. To ascertain whether anthropometric characteristics are relevant to the progression of the swimmers, several body measurements were taken including height, bodymass, arm-span, sitting-height, skinfold thicknesses, limb lengths, girths, and breadths. The body composition was then calculated using various formulas. The time of 100-m butterfly speed performance was measured during the national winter competition over 6 days, as it represents the peak of performance of the Tunisian Championship established under rigorous conditions. 


\section{Subjects:}

Prior to the start of the study, the board members of the clubs, the coaches, and the swimmers were fully informed about the aims of the research. A total of one hundred sixty seven healthy competitive youth swimmers (Male [ $n=103$; age: $13.1 \pm 2.8$ years]; female [ $n=64$; age: $13.6 \pm$ 2.6 years] took part in this study. They were currently competing at the national level. All subjects were classified as experienced swimming athletes involving six to nine training sessions per week $6.3 \pm$ 1.1.Written informed assent (children) / consent (legal representatives) were obtained before the start of the study. The study was approved by the Ethics Institutional Review Board of the Higher Institute of Sport and Physical Education of Ksar Said, Tunisia. All procedures related to the current research were in accordance with the latest version of the Declaration of Helsinki.

\section{Procedures}

\section{Anthropometric measurements:}

All the anthropometrical measurements were taken by one trained anthropometrist assisted by a recorder in accordance with standardized procedures of the international society for the advancement of kinanthropometry (ISAK) (Table 1). ${ }^{12}$ Testing was carried out in a standardized order after a proper calibration of the measuring instruments. Each swimmer's height $(\mathrm{m})$ and body-mass $(\mathrm{kg})$ were assessed, to the nearest $0.1 \mathrm{~cm}$ and $0.1 \mathrm{~kg}$, using a SECA stadiometer and a SECA weighing scale (SECA Instruments Ltd, Hamburg, Germany), respectively. Skinfolds measurements (in millimeters) were taken on the right-hand side of the body $^{12}$ at seven sites (the triceps, biceps, subscapular, supraspinale, mid abdominal, front thigh, and medial calf sites) using Harpenden skinfold calipers (Harpenden Instruments, Cambridge, UK). "The right side of the body is always used for measurements irrespective of the preferred side of the subject. ${ }^{12}$ Skinfold data, alongside the skinfold equation of Slaughter et al. ${ }^{13}$ were used to estimate body-fat-mass and fat free mass. The following limb-lengths girths and breadths were assessed: arm-span, upper-limb-length, upper-arm, lower-arm, handlengths, lower-limb-length, thigh-length, leg-length, foot-length, arm-relaxed-girth, forearmgirth, wrist-girth, thigh-girth, calf-girth, ankle-girth, biacromial, and biiliocristal-breadths.

\section{Performance time:}

The swimming times and/or speeds expressed in seconds and meters per second $\left(\mathrm{m} . \mathrm{s}^{-1}\right)$ were adopted as our measures of the performance and were performed in a 25 -m swimming pool. Performance was measured with a high technology semi-automatic electronic timing (Omega, Switzerland) and was extracted for all subjects from the official results published by the 
Tunisian swimming Federation during the Winter National Championships. Water temperature was kept between 25 and 28 degrees Celsius $\left({ }^{\circ} \mathrm{C}\right)$, as determined by Federation Internationale De Natation. $^{14}$

\section{--Table 1 near here--}

\section{Statistical analyses}

To indicate the most appropriate body-size characteristics [consisting of body-mass (M), fatfree-mass (FFM), fat-mass (FM), height $(\mathrm{H})$, limb-lengths, girths or breadths (L)] related with $100-\mathrm{m}$ butterfly speed performance, we adopted the following proportional multiplicative model with allometric body size components, similar to that used to model 100-m personal best swim speeds measured in front crawl in children and adolescents having controlled for age. $^{5}$

This multiplicative, allometric model has a long history in physical anthropology, ${ }^{15}$ and biology, ${ }^{16}$ and a recent call has been made for consideration within molecular biology and gene expression investigations because human size, and what it involves, will always be of concern. $^{5}$ This model has been systematically used to partition out differences in size in efficient ways, such as differences in VO2 peak ${ }^{17}$ and in a variety of motor tests. ${ }^{5}$

The multiplicative model:

Butterfly speed $\left({\mathrm{m} . \mathrm{s}^{-1}}^{-1}=\mathrm{a} \cdot(\mathrm{M})^{\mathrm{k}_{1}} \cdot(\mathrm{H})^{\mathrm{k}_{2}} \cdot \Pi\left(\mathrm{L}_{\mathrm{i}}\right)^{\mathrm{k}_{\mathrm{i}}} \cdot \exp \left(\mathrm{b} \cdot \operatorname{age}+\mathrm{c} \cdot \operatorname{age}^{2}+\mathrm{d} \cdot \mathrm{FM}\right) \cdot \varepsilon\right.$.

where ' $\mathrm{a}$ ' is a constant and $\Pi\left(\mathrm{L}_{\mathrm{i}}\right)^{\mathrm{k}_{\mathrm{i}}}(\mathrm{i}=3,4, \ldots, \mathrm{n})$ represents the product of all limb segmentlengths, girths or breadths measurements raised to the power $k_{i}$; with $i=3$ to $i=n$ denotes the full range of limb lengths, girths, and breadths recorded for the swimmers(for the full list, see anthropometric measurements paragraph).

The advantages of this model are to have proportional body size components and the flexibility of a quadratic in age within an exponential term that will assure that the 100-m butterfly speed performance will always remain nonnegative irrespective of the subjects' age. Note that " $\varepsilon$ " the multiplicative error ratio, also assumes the error will increase in proportion to the athlete's swimming performance. The model (Equation 1) can be linearized with a log

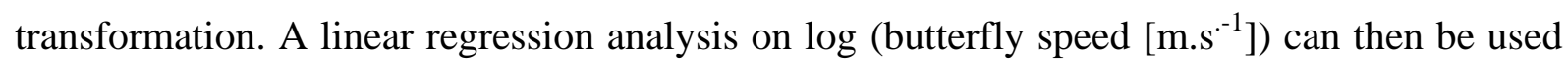
to estimate the unknown parameters of the log transformed model: 
$\log \left(\right.$ butterfly speed $\left.\left(\mathrm{ms}^{-1}\right)\right)=\mathrm{k}_{1} \cdot \log (\mathrm{M}) \mathrm{k}_{2} \cdot \log (\mathrm{H})+\Pi \mathrm{k}_{\mathrm{i}} \cdot \ln \left(\mathrm{L}_{\mathrm{i}}\right)+\mathrm{a}+\mathrm{b} \cdot \mathrm{age}+\mathrm{c}^{- \text {age }^{2}}+\mathrm{d} \cdot \mathrm{FM}+$ $\log (\varepsilon)(2)$

Having fitted the saturated model (all available body size variables), an appropriate "parsimonious" model can be obtained using "backward elimination", 5 in which the least important (non significant) body size and limb segment length, girth, and breadth variable at each step are dropped from the current model. A parsimonious model is a model that accomplishes a desired level of explanation or prediction with as few predictor variables as possible. Further categorical or group differences within the population (e.g., genders) can be explored by allowing the constant intercept parameter $\ln (a)$ in equation 2 to vary for each group (where ln refers to natural logarithms).

\section{RESULTS}

Table 2 shows the parsimonious solution to the backward elimination regression analysis of $\ln \left(\right.$ Butterfly speed $\left.\left[\mathrm{m}_{\mathrm{s}} \mathrm{s}^{-1}\right]\right)$. The multiplicative allometric model relating $100-\mathrm{m}$ butterfly speed performance $\left(\mathrm{m} . \mathrm{s}^{-1}\right)$ to the different anthropometric measurements estimated that fat-mass (as a whole body size dimension), two upper-limb lengths (forearm -length and arm-span), two breadths (biacromial and biiliocristal-breadths) and two girths (calf and ankle-girth) as significant predictors of log-transformed swim performance, together with a significant quadratic in age (Figure. 1).

--Figure 1 near here--

--Table 2 near here-- 


\section{DISCUSSION}

In this study we have adopted a proportional allometric model to estimate the most appropriate body size characteristics related to 100 -m butterfly speed performance in 167 national swimmers. Several studies indicated a relatively high association between anthropometric characteristics and swimming performance in young swimmers. ${ }^{3,4}$ The present investigation showed that anthropometric measurements are strongly associated with 100-m butterfly speed performance. Additionally, results indicated that male butterfly speed performance is $5.6 \%$ faster than female elite swimmers. Our findings are in accordance with those of Kennedy et al. ${ }^{18}$ who found that males usually swim faster (about $10 \%$ on average) than their female counterparts in the preliminary heats of the four 100-meter swimming events (backstroke, breaststroke, butterfly, and freestyle) during the Seoul Olympic Games (1988). For instance, East, ${ }^{19}$ found that male swimmers had longer stroke lengths but similar stroke rates than their female counterparts. The same author concluded that the longer stroke length produced by men was most likely the result of greater propulsive force.

Our results demonstrated that fat-mass was the only whole body-size characteristic negatively associated with butterfly speed. The disadvantage of having higher fat-mass suggests that swimmers require greater fat-free-mass, therefore, they require greater muscularity to propel themselves faster through water, having controlled for differences in age.

Therefore, having a greater fat-free-mass to enhance swimming performance is supported by previous findings ${ }^{5,20}$ and clearly indicates that fat-free-mass contributed significantly to the prediction of propulsion force, which may translate to improve performance in the butterfly stroke in young swimmers. However, Chatard et al. ${ }^{21}$ revealed that female swimmers were more buoyant and tended to remain more horizontal in static position. The same authors attribute their findings to the larger percentage of body fat and to a different distribution of these adipose tissues. In addition, several studies in the literature ${ }^{22,23}$ revealed that women have lower energy cost than men during swimming and their higher economy is traditionally attributed to a smaller hydrodynamic resistance due to their smaller size, larger percentage of body fat in comparison to male swimmers.

Height and body-mass did not contribute significantly to the allometric model, suggesting that the advantage of longer levers was either limb-segment length, girth or breadth specific rather than having a more general whole body-size advantage.

In their recent study, Nevill et al. ${ }^{5}$ established that longer lever length (upper-arm and lower leg) is potentially mechanically disadvantageous in some ways in front crawl performance because the involved muscles have to exert greater force and, hence, use greater energy. 
However, a longer lever length increases reach and the distance available for generation of propulsion, countering the greater energy requirement of using fewer strokes.

Based on the consideration mentioned above, the most important finding from the allometric model reported in our study (Table 2) is the advantage of having greater limb segment length ratio [i.e., arm ratio $=($ arm-span $) /($ forearm $)$ ] and the advantage of having greater limb girth ratio [i.e., girth ratio $=($ calf-girth $) /($ ankle-girth $)]$. Moreover, Grimston \& Hay ${ }^{24}$ reported that the dimensions of body segments, such as the upper limbs or lower limbs lengths, influence the mechanics of swimming technique and muscle activity. In a similar study Togashi \& Nomura ${ }^{25}$ has shown that faster butterfly swimmers present a higher extension of the elbow at the upsweep, in order to increase the duration of this propulsive phase. The present results are in agreement with those of Geladas et al. ${ }^{3}$ and Saavedra et al. ${ }^{26}$ who found that swimmers with a large arm-span glide better through the water which benefits swimming efficiency (i.e., longer stroke length). The increase in the relative duration of the pull phase allowed the use of high propulsive forces, hence greater body velocity. ${ }^{27}$ So, higher swim velocities are achieved by increasing the propulsive force during the final actions of the underwater stroke cycle. ${ }^{28}$ Thus, high-level swimmers have a wider arm-span, allowing them to achieve a higher stroke length, which imposes a higher velocity, stroke index, and critical velocity, and therefore, a faster performance. In this context, Barbosa et al. ${ }^{1}$ revealed that indicators of motor process, as stroke rate and stroke length, are widely used to characterize technical performance in swimming and their interaction determines swimming velocity. While the velocity is a product of stroke frequency (SF) and stroke length (SL) ${ }^{29}$ Increases or decreases in velocity are due to a combined increase or decrease in SF and SL, respectively. ${ }^{29}$ One other parameter often used is the stroke index (SI), considered as a valid indicator for swimming efficiency. ${ }^{30}$ This index assumes that, at a given velocity, the swimmer that moves the greatest distance per stroke has the most efficient swimming technique. In addition, our findings demonstrate the importance of having shorter forearm length for better 100-m butterfly speed performance. This is supported by previous study ${ }^{31}$ that indicated that swimming with a closer elbow angle and subjects with a shorter arm length have naturally a better swimming technique with respect to those with longer upper limbs.

Therefore, it seems crucial to emphasize the importance of teaching and learning the correct swimming technique from the early years of swimming training.

We also identified that the ankle-girth made a negative contribution whereas the calf-girth made a positive contribution to the prediction of 100-m butterfly speed performance. During the race, an underwater phase of 15 meters is allowed after the start and after every turn. 
During this underwater phase the resistance is diminished by adopting a 'streamlined' position characterized by an elongated posture with arms extended forward with hands pronated and overlapping, and the feet together and plantar flexed. ${ }^{32}$ Therefore, kicking efficiently in this phase (dolphin kick) is extremely important. The dolphin kick that is mainly used in the butterfly stroke can be performed in different positions such as prone, dorsal and lateral. This prone dolphin kick consists of two phases: the upward kick, with feet and legs moving towards the surface of the water (also called the flexion kick or upbeat), and the downward kick, with feet and legs moving towards the bottom of the swimming pool (also called the extension kick or down kick). ${ }^{33}$ During the down kick, an extension of the knee is combined with a plantar flexion of the ankle, which is a smoother wave-like motion compared to the upward kick. Hereby, acceleration occurs as a reaction on water that is deflected to the back by the feet, causing propulsion. ${ }^{34}$ It has been demonstrated that most of the thrust is produced by the feet and that the thrust produced during the down kick is much larger than during the upward kick. ${ }^{35}$ Despite the frequent usage of this technique, the factors determining the effectiveness of the dolphin kick are rather unclear. The difference in performance level has a lot to do with skills, ${ }^{36}$ but physical abilities might have an influence as well. However, a recent review showed that the effects of most of the previous investigated parameters need further investigations. ${ }^{37}$

Therefore, having a greater ankle-girth impairs performance so it has been suggested that increased joint flexibility enables the swimmer to achieve a greater range of motion (ROM). ${ }^{38}$ In the same context Cohen el al. ${ }^{35}$ revealed that Swimmers require good plantar flexion of the ankles. The same authors found a significant effect between ankle flexibility and propulsive force which giving swimmers a great range of motion in dolphin kick.

In contrast, our findings revealed that an increase in a calf-girth or volume would increase the $100 \mathrm{~m}$ butterfly speed performance. These results are in accordance with those recently established by Nevill et al. ${ }^{5}$. According to the same author, the advantage of having lower fat mass suggests that greater muscularity is required by swimmers to propel themselves faster through water, having controlled for differences in age. They, also, showed that stroke rate may be influenced by the inertial properties of the limbs, particularly mass and distribution of mass.

Our results also revealed that having greater biacromial and biiliocristal breadths are positive key anthropometric indicators associated with better butterfly speed performance (Table 2). 
These findings are supported by those of Geladas et al. ${ }^{3}$ who revealed that swimming sprint time was significantly correlated with biacromial $(r=-0.61, p<0.01)$ and biiliocristal-breadths $(\mathrm{r}=-0.46, \mathrm{p}<0.01)$ in boy swimmers. These findings may all be related to the fact that swimmers with broad shoulders are better suited for high power output in the water. ${ }^{40}$

Finally Quadratic relationship between log-transformed 100-m butterfly stroke speed and age was required in the final parsimonious model, implying that children, who are older than their counterparts, have a great advantage at swimming but this advantage begins to peak as the swimmers approach their early 20 years.

Some methodological limitations related to the current study warrant discussion. For instance, biomechanical testing methods should be implemented in future studies to obtain an in-depths knowledge regarding the allometric associations between biomechanical, shape, and 100-m butterfly speed performance. In addition, variables from other domains that may also play an important role in swimmers' performance (e.g. kinematic, hydrodynamics, genetics, strength and conditioning) were not taken into consideration in the present study.

\section{Practical applications}

Findings from the present study suggested that the 100-m butterfly speed performance of elite-level swimmers was strongly negatively associated with fat mass and positively associated with the segment length ratio [(arm-span)/(forearm-length)] and girth ratio [(calfgirth)/(ankle-girth)], having controlled for the developmental changes in age.

From a practical point of view, the present results highlighted the crucial importance for coaches and scientists to take into consideration the anthropometric measurements for talent identification or athlete monitoring. In addition, these results allow to orienting the swimmers in the appropriate stroke. Coaches and scientific community would, also, benefit from an awareness of the abovementioned segment length ratios. How such limb length and girth limb length ratio relate to swimming performance over time would be an interesting future research avenue, although a longitudinal design would be needed to accomplish this. Finally, identification of these ratios was made possible by adopting a multiplicative allometric model that was able to confirm, theoretically, that swim speeds are nearly independent of body size. 


\section{Acknowledgments}

The authors are pleased to thankfully acknowledge the athletes and their trainers who willingly and patiently contributed to this study. Also, we would like to thank and express our gratitude to Zied Kerdaoui for his help with data collection. 


\section{References}

1. Barbosa TM, Costa M, Marinho JD, Coelho M, Moreira M, Silva AJ. Modeling the links between young swimmer's performance: energetic and biomechanical profiles. Pediatr Exerc Sci 2010; 22:379-391.

2. Fritzdorf SG, Hibbs A, Kleshnev V. Analysis of speed, stroke rate, and stroke distance for world-class breaststroke swimming. J Sport Sci 2009; 27:373-8.

3. Geladas N, Nassis GP, Pavlicevic S. Somatic And Physical Traits Affecting Sprint Swimming Performance In Young Swimmers. Int J Sports Med 2005; 26: 139-144.

4. Jurimae J, Haljaste K, CicchellaA, Latt E, Purge P, Leppik A, Jurimae T. Analysis of Swimming Performance From Physical, Physiological, and Biomechanical Parameters in Young Swimmers. Pediatr Exerc Sci 2007; 19: 70-81.

5. Nevill AM, Oxford SW, DuncanMJ. Optimal Body Size and Limb Length Ratios Associated with 100-m Personal-Best Swim Speeds. Med Sci Sport Exercise 2015; 47, 1714-8.

6. Avlonitou E. Somatometric variables for preadolescent swimmers. J Sports Med Phys Fit 1994;34: 185-191.

7. Perez AJ, Bassini CF, Pereira Bmf, Sarro Kj. Correlation Between Anthropometric Variables And Stroke Lenght And Frequency. In Swimmers Of Espirito Santo 2011;10: 19-27.

8. Lätt E, Jürimäe J, Mäestu J, Purge P, Rämson R, Haljaste K, KeskinenKL, Rodriguez FA, Jürimäe T. Physiological, biomechanical and anthropometrical predictors of sprint swimming performance in adolescent swimmers. J Sports Sci Med 2010; 9:398404.

9. Morais JE, Jesus S, Lopes V, Garrido N, SilvaA, Marinho D, Barbosa TM. Linking selected kinematic,anthropometric and hydrodynamic variables to young swimmer performance. Pediatr Exerc Sci 2012; 24:649-64.

10. Nevill AM, Tsiotra G, Tsimeas P, Koutedakis Y. Allometric Associations Between Body Size, Shape, and Physical Performance of Greek Children. Pediatr Exerc Sci 2009;21, 220-232.

11. Carlsson T, Carlsson M, Hammarstrom D, Malm C, Tonkonogi M. Scaling of upperbody power output to predict time-trial roller skiing performance. J Sport Sci 2013; 31(6):582-8. 
12. Stewart A, Marfell-Jones M, Olds T, de Ridder H. International Standards for Anthropometric Assessment. Lower Hutt, New Zealand: ISAK ; 2011; pp. 57-72.

13. Slaughter MH, Lohman TG, Boileau RA, Horswill CA, Stillman RJ, VanLoan MD, Bemben DA. Skinfold equations for estimation of body fatness in children and youth. Hum Biol 1988; 60: 709-23.

14. Fédération Internationale De Natation (FINA). Talent identification programmes. 2014 [cited 18 September 2014]. Available from: http://www.fina.org/.

15. Fleagle J. Size and Scaling in Primate biology. In: Jungers W, editor. Size and adaptation in primates. New York: Plenum Press ; 1985.

16. Bown J, West G. Scaling in Biology. New York: Oxford University Press; 2000.

17. Batterham A, George K, Mullineaux D. Allometric scaling of left ventricular mass by body dimensions in males and females. Med Sci Sports Exerc 1997; 29: 181-186. PMID: 9044220.

18. Kennedy P, Brown P, Somadeepti N, Chengalur R, Nels C. Analysis of male and female olympic swimmers in the 100- Meter events. Int J Sport Biomech 1990; 6, 187197.

19. East DJ. Swimming: An analysis of stroke frequency, stroke length and performance. NZ J Health Phys Ed Recr 1970; 3, 16-27.

20. Rushall BS, Springings EJ, Holt LE, Cappaert JM. A re-evaluation of forces in swimming. J Swim Res 1994; 10: 6-30.

21. Chatard JC, Lavoie JM, Lacour JR. Energycost of front crawl swimming in women. Eur J Appl Physiol 1991 ; 63, 12-16.

22. Chatard JC, Lavoire JM, Lacour JR. Analysis of determinants of swimming economy in front crawl. Eur J Appl Physiol Occup Physiol 1990; 61; 88-92.

23. Zamparo P, Capelli C, Cautero M, di Nino A. Energy cost of front crawl swimming at supra-maximal speeds and underwater Torque Characteristics in young swimmers. Eur J Appl Physiol 2000; 83: 487-491.

24. Grimston SK, Hay JG. Relationships among anthropometric and stroking characteristics of college swimmers. Med Sci Sport Exerc 1986; 18, 60-8. 
25. Togashi T, Nomura T. A biomechanical analysis of the swimmer using the butterfly stroke. In: MacLren D, Reukky T, Lees A, editors. Biomechanics and Medicine in Swimming VI . London ;1992.p.87-91.

26. Saavedra JM, Escalante Y, Rodriguez FA. A multivariate analysis of performance in young swimmers. Pediatr Exerc Sci 2010; 22(1):135-51.

27. Mason BR, Tong Z, Richards RJ. Propulsion in the butterfly stroke. In: MacLaren D, Reilly T, Less A editors. Swimming Science VI. London, England: E \& FN SPON; 1992.p.81-86.

28. Barbosa TM, Marinho DA, Costa MJ, Silva AJ. Biomechanics of Competitive Swimming Strokes. Biomechanics in Applications, Dr Vaclav Klika, Editors. ISBN; 2011.

29. Craig A, Pendergast D. Relationships of stroke rate, distance per stroke and velocity in competitive swimming. Med Sci Sports Exerc 1979;11.

30. Costill DL, Kovaleski J, Porter D, Kirwan J, Fielding R, King D. Energy expenditure during front crawl swimming: predicting success in middle-distance events. Int $\mathbf{J}$ Sports Med 1985; 6:266-270.

31. Zamparo P, Pendergast DR, Mollendorf J, Termini A, Minetti AS. An energy balance of front crawl. Eur J Appl Physiol 2006;94(1-2):134-44.

32. Naemi R, Easson WJ, Sanders RH. Hydrodynamic glide efficiency in swimming. J Sci Med Sport 2010; 13(4):444-51.

33. Alves F, Lopes P, Veloso A, Martins-Silva A. Influence of body position on dolphin kick kinematics. In Proceedings of the XXIV ISBS Symposium. Salzburg, Austria. 2006.

34. Colman V, Persyn U, Ungerechts BE. A mass of water added to the swimmer's mass to estimate the velocity in dolphin-like swimming below the water surface. In Biomechanics and medicine in swimming. III. Proceedings of the VIII internationalsymposium on biomechanics and medicine in swimming, Jyväskylä. 1994. p. 89-94.

35. Cohen RCZ, Cleary PW, Mason BR. Simulations of dolphin kick swimming using smoothed particle hydrodynamics. Hum Mov Sci 2012; 31(3), 604-619.

36. Costill DL. Maglischo EW, Richardson AB. Handbook of Sports Medicine and Science: Swimming. Blackwell Scientific Publications. Oxford, UK: 1992.

37. Connaboy C, Coleman S, Sanders RH. Hydrodynamics of undulatory underwater swimming: A review. Sports Biomech 2009; 8: 360-380. 
38. Counsilman JE. The Science of Swimming. Englewood Cliffs, Nj: Prentice-Hall 1968.

39. Cohen RC, Cleary PW, Mason BR. Simulations of dolphin kick swimming using smoothed particle hydrodynamics. Human Movement Science 2012; 31(3), 604-619. http://dx.doi.org/10.1016/j.humov.2011.06.008

40. Carter JEL, Ackland TR. Kinanthropometry in aquatic sports: A study of world class athletes. Champaign, IL: Human Kinetics ;1994. 
FIGURE 1-Quadratic relationship between log-transformed 100-m butterfly stroke speed and age among for youth swimmers

Table 1:Descriptive Statistics for subjects' characteristics.

Table 2. Estimated body size and limb segment length parameter (B) obtained from regression analysis predicting log-transformed 100-m butterfly.

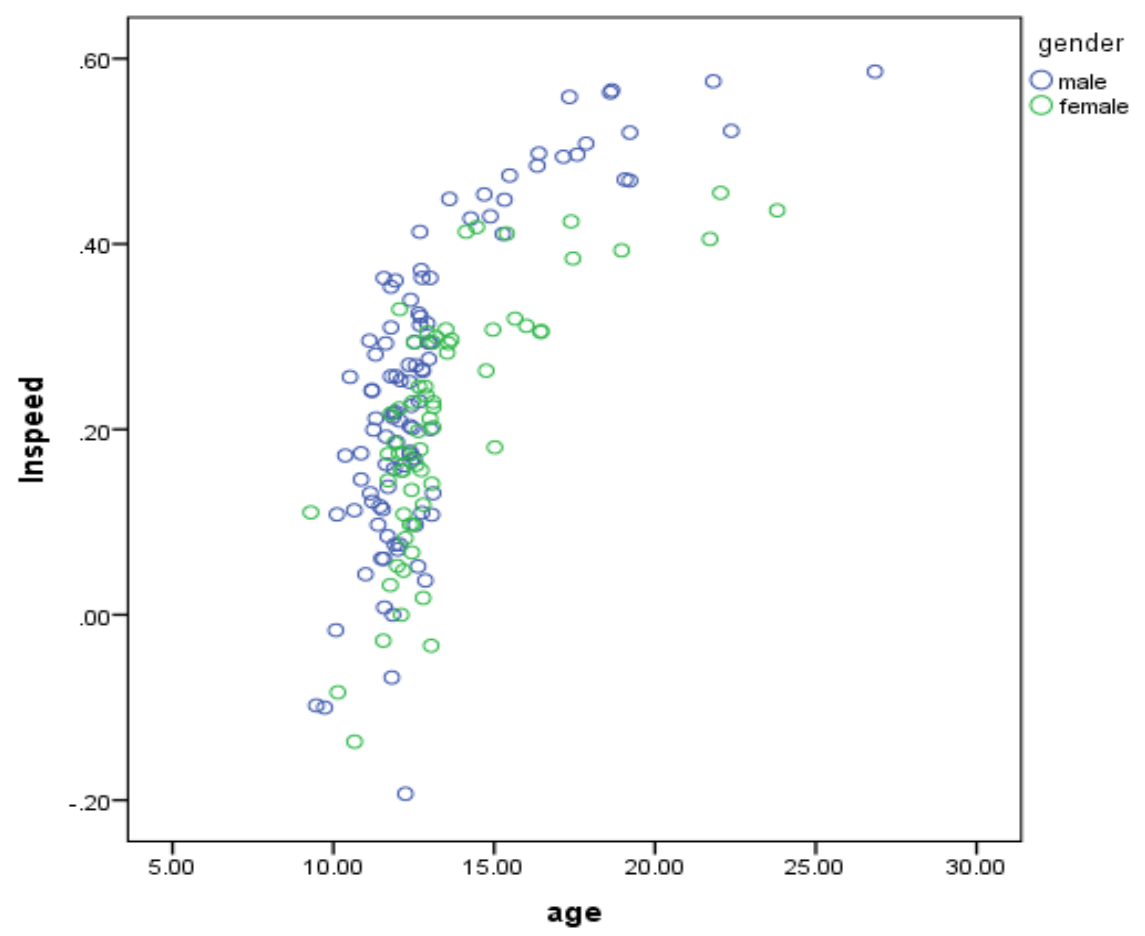


Table 1: Descriptive Statistics for subjects' characteristics.

\begin{tabular}{|c|c|c|}
\hline & Boys & Girls \\
\hline Age (years) & $13.1 \pm 2.8$ & $13.6 \pm 2.6$ \\
\hline Body-Mass (kg) & $50.0 \pm 14.2$ & $49.3 \pm 9.2$ \\
\hline Stature $(\mathrm{cm})$ & $158.3 \pm 12.7$ & $157.9 \pm 8.9$ \\
\hline Sitting Height (cm) & $78.6 \pm 7.1$ & $79.0 \pm 6.6$ \\
\hline Body-Fat $\%$ & $16.6 \pm 5.2$ & $18.6 \pm 3.7^{*}$ \\
\hline Fat-Mass (kg) & $8.4 \pm 3.6$ & $9.2 \pm 2.7$ \\
\hline Fat-Free-Mass (kg) & $41.7 \pm 12.3$ & $40.1 \pm 7.4$ \\
\hline Body-Mass Index kg.m ${ }^{-2}$ & $19.6 \pm 2.9$ & $19.6 \pm 2.2$ \\
\hline Upper-Limb-Length $(\mathrm{cm})$ & $73.3 \pm 6.2$ & $73.01 \pm 4.5$ \\
\hline Upper-Arm-Length $(\mathrm{cm})$ & $30.8 \pm 2.9$ & $31 . \pm 2.3$ \\
\hline Lower-Arm-Length $(\mathrm{cm})$ & $24.3 \pm 2.1$ & $24.2 \pm 1.7$ \\
\hline Hand-Length (cm) & $19 . \pm 1.6$ & $18.9 \pm 1$ \\
\hline Lower-Limb-Length (cm) & $85.9 \pm 6.6$ & $86.4 \pm 5.7$ \\
\hline Thigh-Length (cm) & $41.4 \pm 3.1$ & $42.8 \pm 3.4^{*}$ \\
\hline Leg-Length (cm) & $44.2 \pm 3.5$ & $43.7 \pm 2.7^{*}$ \\
\hline Foot-Length (cm) & $26.2 \pm 1.8$ & $25.2 \pm 1.1^{*}$ \\
\hline Arm-Relaxed-Girth (cm) & $24.9 \pm 3.8$ & $24.6 \pm 2.2$ \\
\hline Forearm-Girth $(\mathrm{cm})$ & $22.7 \pm 3$ & $21.9 \pm 1.6^{*}$ \\
\hline Wirst-Girth (cm) & $15.5 \pm 1.4$ & $15 \pm 0.7 *$ \\
\hline Thigh-Girth (cm) & $46.4 \pm 7.1$ & $47.7 \pm 4.4$ \\
\hline Calf-Girth (cm) & $32.3 \pm 3.4$ & $31.9 \pm 2.6$ \\
\hline Ankle-Girth (cm) & $21.2 \pm 1.8$ & $20.7 \pm 1.2 *$ \\
\hline Biacromial-Breadth $(\mathrm{cm})$ & $43.8 \pm 3.5$ & $43.7 \pm 2.1$ \\
\hline Biiliocristal-Breadth (cm) & $26.3 \pm 2.7$ & $26.5 \pm 2.3$ \\
\hline Arm-Span $(\mathrm{cm})$ & $161.1 \pm 15.6$ & $160.6 \pm 10.6$ \\
\hline
\end{tabular}

* Denotes significant differences between boys and girls $(\mathrm{p}<0.05)$. 
TABLE 2. Estimated body size and limb segment length parameter (B) obtained from regression analysis predicting log-transformed 100-m butterfly speed.

\begin{tabular}{|lcccc|}
\hline \multicolumn{1}{|c}{ Model } & B & Std. Error & p & $\begin{array}{c}\text { 95\% Confidence } \\
\text { Interval for B }\end{array}$ \\
\hline Ln(a) & -4.908 & 0.584 & $<0.001$ & -6.062 to -3.754 \\
Female & -0.056 & 0.015 & $<0.001$ & -0.085 to -0.027 \\
Ln(lower-Arm Length) & -0.356 & 0.142 & 0.013 & -0.637 to -0.075 \\
Ln(Arm Span) & 0.428 & 0.148 & 0.004 & 0.135 to 0.720 \\
Ln(Calf Girth) & 0.573 & 0.164 & 0.001 & 0.249 to 0.897 \\
Ln(Ankle-Girth) & -0.412 & 0.146 & 0.006 & -0.701 to -0.123 \\
Ln(Biacromial Breath) & 0.489 & 0.160 & 0.003 & 0.174 to 0.804 \\
Ln(Biiliocristal Breath) & 0.292 & 0.090 & 0.001 & 0.114 to 0.469 \\
Age & 0.073 & 0.022 & 0.001 & 0.030 to 0.117 \\
Age & -0.002 & 0.001 & 0.013 & -0.003 to -0.001 \\
Fat-Mass & -0.011 & 0.003 & $<0.001$ & -0.017 to -0.006 \\
\hline
\end{tabular}

